\title{
Effectiveness and Safety of Wide Awake Local Anesthesia no Tourniquet (WALANT) Technique in Hand Surgery
}

\author{
MIHAELA PERTEA ${ }^{1,3}$, OXANA MADALINA GROSU ${ }^{1,2 *}$, BOGDAN VELICEASA $^{1,3}$, NATALIA VELENCIUC ${ }^{1,4}$, PETRU CIOBANU2*, \\ RAZVAN TUDOR ${ }^{5}$, VLADIMIR POROCH ${ }^{1,4 *}$, SORINEL LUNCA ${ }^{1,5}$ \\ 1.Grigore T. Popa University of Medicine and Pharmacy, Faculty of Medicine, 16 Universitatii Str., 700115, Iasi, Romania \\ 2.Clinic of Plastic and Reconstructive Microsurgery, Sf. Spiridon Emergency Hospital, 1 Independentei Sq., 700111, Iasi, Romania \\ 3.Clinic of Orthopaedics and Traumatology, Sf. Spiridon Emergency Hospital, 1 Independentei Sq., 700111, Iasi, Romania \\ 4.Palliative Care Department, Regional Institute of Oncology, 2-4 G-ral Berthelot Str., 700483, Iasi, Romania \\ 5.Second Clinic of Surgical Oncology, Regional Institute of Oncology, 2-4 G-ral Berthelot Str., 700483, Iasi, Romania \\ 6.Department of Orthopaedics and Traumatology, Emergency County Hospital, 233 Stefan cel Mare Str.,730006, Vaslui, Romania
}

The aim of the study was to confirm the effectiveness and safety of wide awake local anesthesia no tourniquet (WALANT) technique in hand surgery, to present our results and to encourage its use on Romania and all over the world. The study group consisted of 120 patients in which local anesthesia with 1\% lidocaine and 1: 100,000 epinephrine solution was used. The conditions requiring surgery were Dupuytren disease (DD) stages II and III affecting one or two digital rays, carpal tunnel syndrome (CTS), trigger finger (TF), rupture of the flexorpollicis longus (FPL) tendon. The amount of anesthetic used, onset time, intraoperative bleeding, surgeon's comfort during surgery, patient's comfort, operative time, the immediate postoperative complications and length of hospital stay were evaluated, correlations between these parameters being made with the help of SPSS 20.0 software using regressions (ANOVA), and taking into account Pearson correlation coefficients with statistical significance, alpha at most .05 and $\mathrm{Cl} 95 \%$. In the group of 120 operated patients ( 58 men - $M$ and 62 female $-F)(M / F$ ratio $=0.93)$, no cases of digital necrosis or other vascular complications were recorded. Also, the absence of tourniquets did not result in intraoperative bleeding causing discomfort to the surgeon. The amount of anesthetic varied, being less than that recommended in the literature in approximately $40 \%$ of the cases. In all cases, patient comfort and satisfaction were highest, and length of hospital stay was several hours. Phentolamine, an antidote used to reverse the effects of epinephrine, was not used in any case. The correlation coefficient between the amount of anesthetic and waiting time $=0.3372(p=0.0001)$ - positive, direct, moderate, and statistically significant correlation. The correlation coefficient between the amount of anesthetic and length of hospital stay = $0.2700(p=0.002)$ - positive, direct, weak and statistically significant correlation. Correlation coefficient between age and length of hospital stay $=0.1361(p=0.1380)$ - positive, direct, weak correlation, but statistically insignificant. WALANT technique is safe and has many advantages: no need it is not necessary to use the tourniquet and intravenous sedation, surgeon and patient comfort is maximum, there is no risk of finger necrosis, intraoperative collaboration and last but not the least, hospital stay is short and costs are minimal.

Keywords: local anesthesia, epinephrine, Dupuytren disease (DD), carpal tunnel syndrome (CTS), trigger finger(TF)

In recent years, the interest in the use of local anesthesia in hand surgery has increased considerably. Although fallen into disgrace for a long time because of the supposition of being the cause of digital necrosis when injected locally, epinephrine proves to be a real help in local anesthesia when combined with $1 \%$ lidocaine. The allowed local anesthetic doses may be doubled when associated with epinephrine because absorption is slower and reaching toxic plasma concentrations is avoided. Over time, epinephrine has also been proven safe to use, not causing such complications as digital necrosis [1]. In a large 2005 study of 3110 patients, Lalonde used local anesthesia with a solution of $1 \%$ lidocaine and 1: 100,000 epinephrine in hand surgery, with no case of digital necrosis being reported [2]. In 2007 Fitzcharles - Boweet et al. had their own fingers injected with epinephrine to demonstrate that there are no risks related to epinephrine use in fingers [3]. Lalonde defines this technique of local anesthesia with $1 \%$ lidocaine and 1: 100,000 epinephrine as the WALANT (wide awake local anesthesia no tourniquet) technique. It has multiple advantages: simple, safe, fast, no need for sedation or to use tourniquet, maintains a local vasoconstriction which does not alter the accuracy of the surgical technique, provides optimal comfort for both the surgeon and patient, makes possible the intraoperative patient collaboration fortesting of active movement, thus leading to a correct reconstruction of the anatomical elements [2]. Operative time, short hospital stay, minimum use of medical supplies and rapid recovery add the low cost to the advantages of this technique. All these advantages have made the technique to be used in surgeries for CTS, DD, TF, tendon reconstructions and transfers, hand fractures, trapezo-metacarpian joint (TMJ ) arthroplasty, trapeziectomy for TMJ arthritis, distal radius fracture, arthroscopy, ankle fracture and required open reduction and internal fixation (ORIF) [4-11].

\section{Experimental part}

Materials and methods

The study included a group of 120 patients who had undergone hand surgery performed by a single surgeon and were admitted to our clinic between October 2017 and March 2019. On admission, all patients were informed about the therapeutic protocol and informed consent was 
obtained from all patients in the study group. Admission diagnoses of the study patients were: DD (in different stages of disease progression), CTS, TF and posttraumatic FPL tendon rupture. Associated pathologies were hypertension (in differentstages) and diabetes mellitus. In all cases, surgical interventions were performed under local anesthesia using $1 \%$ lidocaine with 1: 100,000 epinephrine solution. $8.4 \%$ sodium bicarbonate buffering was not used in any case. The maximum dose used was $7 \mathrm{mg} / \mathrm{kg}$. To inject the anesthetic a thin $(27 \mathrm{G})$ needle was used.To diminish the pain associated with local anesthetic injections, ice were applied to the skin for $30 \mathrm{sec}-1 \mathrm{~min}$. The anesthetic was injected by inserting the needle perpendicular to the skin fold formed between the surgeon's thumb and index finger. Patients have always been advised to tell the surgeon about experiencing pain or even little discomfort. Initially, $0.3-0.5 \mathrm{~mL}$ were injected just below the dermis. After the patient no longer complained of pain, the remaining anesthetic was injected by advancing the needle more deeply (about $1 \mathrm{~cm}$ ). The amount of anesthetic solution used did not exceed $20 \mathrm{~mL}$ for CTS and $15 \mathrm{~mL}$ for each digital ray affected by DD. As to the mode of administering the anesthetic, not the entire amount was injected from the beginning: in cases with CTS, $10 \mathrm{~mL}$ were injected on each side in the immediate vicinity of the incision site.The remaining $10 \mathrm{~mL}$ were injected into the skin at the periphery of the area where hypoesthesia was already present. The same method was used in patients with DD, the anesthetic being injected in the vicinity of future incisions. In TF cases, no more than 1 $\mathrm{mL}$ anesthetic solution was injected into a digital phalange. During anesthetic injection patients were conscious, cooperative, without receiving sedatives. Onset of anesthesia took 6 to $15 \mathrm{~min}$. Skin blanching and skin insensitivity do occur, the estimation being subjective by testing the patient for pain. In all cases, intra-operative bleeding was minimal, so the use of tourniquet was not necessary. Bleeding was classified as: - when similar to the situation where the tourniquet would have been used, + when minimal bleeding was recorded, and ++ when bleeding was present but did not make it impossible to continue the surgery under the given conditions and the tourniquet was not applied to the arm. Intraoperative pain was objectively assessed by monitoring the vital signs: blood pressure, heart rate, and subjectively by talking with the patient who can describe pain as being non-existent, minimal, bearable or unbearable. Patient comfort was assessed by monitoring the objective signs (blood pressure, pulse) and the subjective reactions of the patient. For the statistical study, considered were the demographic and anatomical variables: sex, age, area of residence, affected hand, and surgical variables: amount of anesthetic solution used, onset time of anesthesia, waiting time for anesthesia, intraoperative bleeding, local pain, length of hospital stay. Statistical processing was performed using the SPSS 20.0 version software, using regressions (ANOVA), taking into account Pearson correlation coefficients with statistical significance, for alpha of at most .05 and $\mathrm{Cl}$ 95\%.

\section{Results and discussions}

We conducted a descriptive study involving a group of 120 patients, of which 58 (48.33\%) men and 62 (51.66\%) women $(M / F$ ratio $=0.93)$, aged 30 to 81 years, (mean age 55.13 years). Of these, $63(52.50 \%)$ patients were diagnosed with CTS, 41 (34.16\%) with DD, $13(10,83 \%)$ with TF, and 3 (3.34\%) with posttraumatic FLP tendon rupture.The demographic data of all study patients revealed a predominance of women, $\mathrm{M} / \mathrm{F}$ ratio $=0.93$ and urban patients,with a total U/R ratio of 1.68. Mean age was 55.13 years $(\mathrm{max} / \mathrm{min}=81 / 30)$; more than two-thirds of the patients were aged $50-59(30.00 \%)$ and $60-69$ years (28.33\%) (tables 1, 2).

In more than half of the cases (52.50\%), the amount of anesthetic used was $20 \mathrm{~mL}$ and over (52.50\%), with an average of $16.67 \mathrm{~mL}$ for the entire study group; calculated by diagnostic subgroups, patients with DD needed the highest amount of anesthetic (mean $=18.63 \mathrm{~mL}$ ) while the lowest amount was administered in patients with TF $(3.07 \mathrm{~mL})$. Mean onset time of anesthesia was 12.15 minutes, faster in patients with FLP tendon rupture (10.67 minutes) and longer in those with DD (13.19 min), but with statistically insignificant differences $(p>0.05)$. Mean waiting time was $13.95 \mathrm{~min}$, the shortest in patients with FLP tendon rupture (10.00 minutes) and longest in those with DD (15.92 $\mathrm{min})$. No case of intraoperative bleeding was reported. Most patients (90.83\%) did not report local pain, but $5.83 \%$ of them described it as moderate and $3.34 \%$ as intense (Table 3).

All obtained results show that no intraoperative bleeding was recorded in the 120 patients who underwent surgery under WALANT, and, consequently, in no case the use of the tourniquet andanesthetist's intervention or administration of sedatives were required, and only 2 (3.34\%) patients complained of moderate pain. ++ pain intensity was recorded in two DD cases: a 41-year-old woman and a 70-year-old man, and in a 59-year-old rural patient diagnosed with CTS. No complications such as

Table 1

DEMOGRAPHIC AND ANATOMIC VARIABLES

\begin{tabular}{|l|l|l|l|}
\hline \multicolumn{2}{|l}{ Variables } & Number & $\%$ \\
\hline \multirow{3}{*}{$\begin{array}{l}\text { Gender } \\
\text { (TOTAL) }\end{array}$} & F & 58 & 48.33 \\
\cline { 2 - 4 } & Urban & 76 & 51.67 \\
\hline Residence area & Rural & 44 & 63.33 \\
\hline (TOTAL) & Mean & 55.13 & 36.67 \\
\hline $\begin{array}{l}\text { Age group } \\
\text { (TOTAL) }\end{array}$ & Max & 81 & n/a \\
\cline { 2 - 4 } & Min & 30 & n/a \\
\cline { 2 - 4 } & $<40$ & 9 & n/a \\
\cline { 2 - 4 } & $40-49$ & 29 & 7.50 \\
\cline { 2 - 4 } & $50-59$ & 36 & 24.17 \\
\cline { 2 - 4 } & $60-69$ & 34 & 30.00 \\
\cline { 2 - 4 } & $\geq 70$ & 12 & 28.33 \\
\hline Hand & Right & 83 & 10.00 \\
\cline { 2 - 4 } (TOTAL) & Left & 37 & 69.16 \\
\hline
\end{tabular}


Table 2

ANATOMIC VARIABLES

\begin{tabular}{|c|c|c|c|c|c|c|c|c|c|}
\hline \multirow{2}{*}{\multicolumn{2}{|c|}{ Variables }} & \multicolumn{2}{|c|}{$\begin{array}{c}\text { Trigger } \\
\text { Finger }(\mathrm{N}=13)\end{array}$} & \multicolumn{2}{|c|}{$\begin{array}{c}\text { Carpian tunnel } \\
\text { syndrome }(N=63)\end{array}$} & \multicolumn{2}{|c|}{$\begin{array}{l}\text { Dupuytren disease } \\
\qquad(\mathrm{N}=41)\end{array}$} & \multicolumn{2}{|c|}{$\begin{array}{l}\text { Tendon flexor lung } \\
\text { police }(\mathrm{N}=3)\end{array}$} \\
\hline & & Number & $\%$ & Number & $\%$ & Number & $\%$ & Number & $\%$ \\
\hline \multirow{3}{*}{ Gender } & $\mathrm{M}$ & 4 & & 22 & & 32 & & 0 & \\
\hline & $F$ & 9 & & 41 & & 9 & & 3 & \\
\hline & $\mathrm{M}: \mathrm{F}=$ & 0.44 & & 0.53 & & 3.55 & & $\mathrm{n} / \mathrm{a}$ & \\
\hline \multirow[t]{3}{*}{ Area } & $\mathrm{U}$ & 10 & & 38 & & 25 & & 3 & \\
\hline & $R$ & 3 & & 25 & & 16 & & 0 & \\
\hline & $\mathrm{U}: \mathrm{R}=$ & 3.33 & & 1.52 & & 1.56 & & $\mathrm{n} / \mathrm{a}$ & \\
\hline \multirow[t]{8}{*}{ Age } & Mean & 57.31 & & 55.36 & & 55.24 & & 39.33 & \\
\hline & Max & 73 & & 81 & & 70 & & 45 & \\
\hline & Min & 45 & & 30 & & 30 & & 30 & \\
\hline & $<40$ & 0 & & 6 & & 2 & & 1 & \\
\hline & $40-49$ & 3 & & 15 & & 9 & & 2 & \\
\hline & $50-59$ & 4 & & 19 & & 14 & & 0 & \\
\hline & $60-69$ & 4 & & 15 & & 14 & & 0 & \\
\hline & $\geq 70$ & 2 & & 8 & & 2 & & 0 & \\
\hline \multirow[t]{3}{*}{ Hand } & Right & 7 & & 49 & & 25 & & 2 & \\
\hline & Left & 6 & & 14 & & 16 & & 1 & \\
\hline & $R: L$ & 1.16 & & 3.50 & & 1.56 & & $\mathrm{n} / \mathrm{a}$ & \\
\hline
\end{tabular}

\begin{tabular}{|c|c|c|c|}
\hline \multicolumn{2}{|l|}{ Variables } & Number & $\%$ \\
\hline \multirow[t]{10}{*}{ Anesthetic solution (mL) } & $\approx 10 \mathrm{~mL}$ & 13 & 10.83 \\
\hline & $10-14 \mathrm{~mL}$ & 1 & 3.34 \\
\hline & $15-19 \mathrm{~mL}$ & 40 & 33.33 \\
\hline & $\geq 20 \mathrm{~mL}$ & 63 & 52.50 \\
\hline & Mean total group(max/min) & $16.67(20 / 2)$ & $\mathbf{n} / \mathbf{a}$ \\
\hline & Mean TF $(\max / \min )$ & $3.07(4 / 2)$ & $\mathrm{n} / \mathrm{a}$ \\
\hline & Mean CTS $(\max / \min )$ & $16.49(20 / 14)$ & $\mathrm{n} / \mathrm{a}$ \\
\hline & Mean DD $(\max / \min )$ & $18.63(20 / 15)$ & $\mathrm{n} / \mathrm{a}$ \\
\hline & Mean TFLP $(\max / \min )$ & $10.67(12 / 10)$ & $\mathrm{n} / \mathrm{a}$ \\
\hline & Mean total group $(\max / \min )$ & $13.38(20 / 3)$ & $\mathbf{n} / \mathbf{a}$ \\
\hline \multirow[t]{8}{*}{ Anesthesia instaling } & $<10 \mathrm{~min}$ & 14 & 11.67 \\
\hline & $10-14 \mathrm{~min}$ & 72 & 60.00 \\
\hline & $15-20 \mathrm{~min}$ & 16 & 28.33 \\
\hline & Mean total group $(\max / \min )$ & $12.15(20 / 8)$ & $\mathbf{n} / \mathbf{a}$ \\
\hline & Mean TF $(\max / \min )$ & $12.23(15 / 8)$ & $\mathrm{n} / \mathrm{a}$ \\
\hline & Mean CTS $(\max / \min )$ & $11.54(15 / 8)$ & $\mathrm{n} / \mathrm{a}$ \\
\hline & Mean DD (max/min) & $13.19(20 / 10)$ & $\mathrm{n} / \mathrm{a}$ \\
\hline & Mean TFLP $(\max / \min )$ & $10.67(12 / 10)$ & $\mathrm{n} / \mathrm{a}$ \\
\hline \multirow[t]{8}{*}{ Waiting time } & $<10 \mathrm{~min}$ & 7 & 5.83 \\
\hline & $10-14 \mathrm{~min}$ & 51 & 42.50 \\
\hline & $15-20 \mathrm{~min}$ & 62 & 51.67 \\
\hline & Mean total group $(\max / \min )$ & $13.95(20 / 8)$ & $\mathbf{n} / \mathbf{a}$ \\
\hline & Mean TF $(\max / \min )$ & $10.31(18 / 8)$ & $\mathrm{n} / \mathrm{a}$ \\
\hline & Mean CTS $(\max / \min )$ & $13.41(20 / 8)$ & $\mathrm{n} / \mathrm{a}$ \\
\hline & Mean DD (max/min) & $15.92(20 / 8)$ & $\mathrm{n} / \mathrm{a}$ \\
\hline & Mean TFLP $(\max / \min )$ & $10(10 / 10)$ & $\mathrm{n} / \mathrm{a}$ \\
\hline \multirow[t]{2}{*}{ Intraoperative bleeding } & Yes & 0 & 0 \\
\hline & No & 120 & 100 \\
\hline \multirow[t]{3}{*}{ Local pain } & 0 & 109 & 90.83 \\
\hline & 1 & 7 & 5.83 \\
\hline & 2 & 4 & 3.34 \\
\hline \multirow[t]{10}{*}{ Length of hospital stay (hours) } & $\leq 8$ & 71 & 59.16 \\
\hline & 12 & 5 & 4.17 \\
\hline & $24-28$ & 12 & 10.00 \\
\hline & $36-48$ & 27 & 22.50 \\
\hline & $72-78$ & 5 & 4.17 \\
\hline & Mean total group $(\max / \min )$ & $19.33(78 / 2)$ & $\mathbf{n} / \mathbf{a}$ \\
\hline & Mean TF $(\max / \min )$ & $3.69(6 / 2)$ & $\mathrm{n} / \mathrm{a}$ \\
\hline & Mean CTS $(\max / \min )$ & $7.46(48 / 4)$ & $\mathrm{n} / \mathrm{a}$ \\
\hline & Mean DD (max/min) & $43.41(78 / 24)$ & $\mathrm{n} / \mathrm{a}$ \\
\hline & Mean TFLP $(\max / \min )$ & $7.33(8 / 6)$ & $\mathrm{n} / \mathrm{a}$ \\
\hline
\end{tabular}

Table 3

SURGICAL VARIABLES 


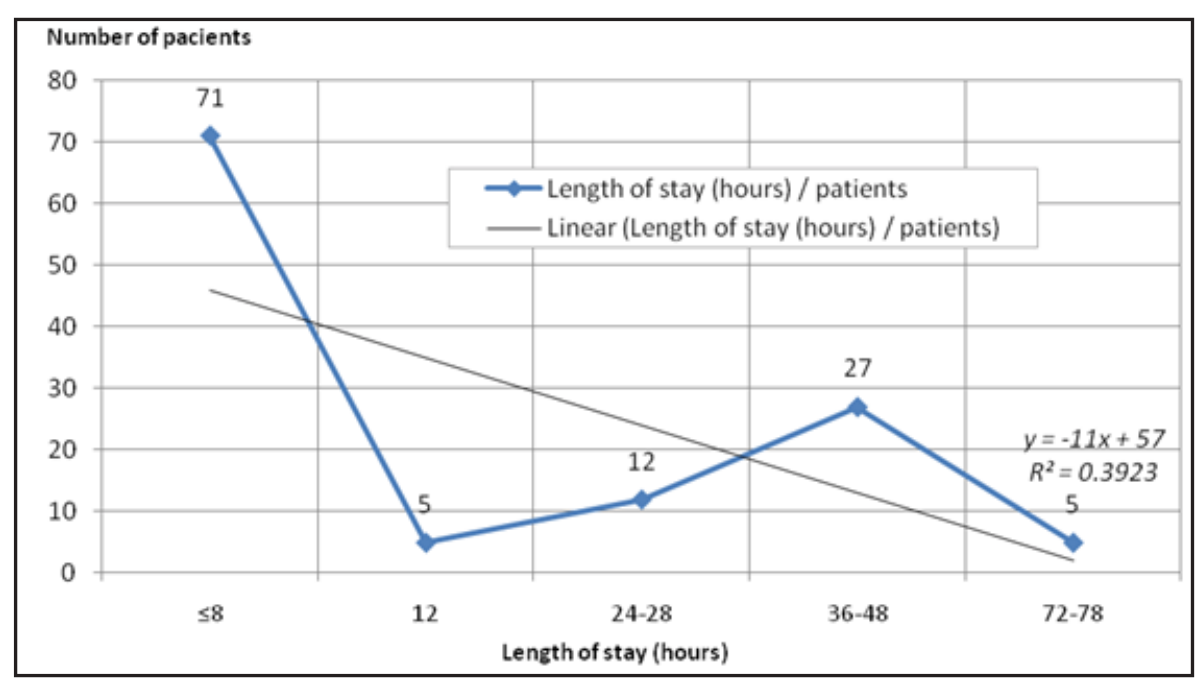

Fig. 1. Length of hospital stay (h)

finger necrosis have been identified in any of these cases. The correlation coefficient between the amount of anesthetic and waiting time was $r=0.3372$, revealing a positive, direct but moderately close, and very statistically significant relationship ( $p=0.0001$ ). The correlation coefficient between the amount of anesthetic and length of hospital stay was $r=0.2700$, showing a positive, direct but w eak correlation, but also statistically significant ( $p=$ 0.002 ). By correlating patient age and length of hospital stay, a correlation coefficient $r=0.1361$ was obtained, which shows that the relationship between these two variables can be positive, direct but weak and statistically insignificant ( $p=0.1380)$, in Figure 1.

The need to perform bloodless surgical procedures, avoidance of the use of sedatives and tourniquet, and the intraoperative collaboration with the patient resulted in an increasing number of studies conducted in view of demonstrating the efficacy and safety of the WALANT technique which in time became broader, with extensive and varied use of this local anesthesia technique.

In Green's Operative Hand Surgery, sixth edition, the authors return to the mentions made in the previous edition related to epinephrine injection into the fingers as a result of Wilhelmi's study of 60 patients in which the anesthetic solution used was 1\% lidocaine with 1: 200,000 epinephrine [12]. This study reported no case of finger necrosis. One of the most extensive studies aimed at demonstrating the safety of using the WALANT technique was the multicenter (six hospital centers) study conducted by Lalonde in 2005 involving 3100 patients and 9 surgeons [2]. The results of this study showed that no case of finger necrosis was recorded and moreover the use of the antidote (phentolamine) was not necessary. In 2007, FitzcharlesBowe went further on with studies showing that even lidocaine with 1: 1000 epinephrine solution does not cause finger necrosis [3]. The efficacy of epinephrineuse for local anesthesia in hand surgery continued to be confirmed in subsequent years; thus, Chow dhry in a2010study of 1111 patients reported no case of finger necrosis [13]. In 2012, Mann and Hammert report a study in which tenorrhaphy and tenolysis surgerieswere routinely performed under local anesthesia (1\% lidocaine and epinephrine), confirming the safety and effectiveness of WALANT technique, tourniquet application and sedation not being required [14].

The name of WALANT technique (wide awake local anesthesia no tourniquet) was given by Lalonde, who continues the studies on the injection technique, amounts of anesthetic solution recommended for each disease, and safe doses [11]. Thus, in 2013, Lalonde stated that the safe dose of $1 \%$ lidocaine and 1: 100,000 epinephrine is $7 \mathrm{mg} / \mathrm{kg}$, and the amounts of anestheticsolution were: 20 CC for CTS, 4 Cc for TF, 15 cc for each digital ray affected by $\mathrm{DD}$, and $40 \mathrm{cc}$ for Bennet fracture and metacarpal fractures [15]. In 2013, McKee and Lalonde demonstrated that the vasoconstrictor effect of epinephrine is recorded at about 25 minutes after injection, thus they recommend that epinephrine injection to be given 25 minutes prior to incision [16].

In our study, we stuck to the maximum allowable dose, but the waiting time between injection and initiation of surgery ranged between 10 and 20 minutes (in $60 \%$ of the cases between 10 and 14 minutes). In order to attenuate injection pain, Lalonde in 2014 and Petro J ose Pires Neto in 2017 suggested to buffer the anesthetic solution with $8.4 \%$ sodium bicarbonate in a 10:1 dilution,warming the anesthetic solution to body temperature, using smallergauge needles, perpendicular injection technique, and slow injection after previously creating pressure on the injection area $[17,18]$. We used thin injection needles in all study cases, respecting the needle size and injection method, but ice was placed on the insertion site for 30 seconds-1 minute prior to injectionto minimize injection pain.In no case was the anesthetic solution buffered with $8.4 \%$ sodium bicarbonate [19]. Using this technique patient comfort during the injection was good. Although no finger necrosis was reported when using the WALANT technique, some authors, such as Zhu in 2017, recommend that phentolamine to be available for use in hand surgery units using this anesthetic technique [20]. In our study, phentolamine use was not required in any patients.

The advantages of WALANT technique are multiple: no use of tourniquet, of which Hutchinson et al., as well as Maury et al. conducting volunteer studies showed that the average upper limb tourniquet tolerance is 13 to 25 minutes $[20,21]$. A prolonged tourniquet time may lead from transient nerve damage to severe neurological deficits. Avoiding the use of tourniquet means improved patient comfort, a comfortable position, and in patients with associated rheumatic diseases the possibility of a slight change in body position on the operating table [22]. In our study, in none of the patients tourniquet application was necessary as no massive bleeding was recorded. Among the advantages of WALANT technique are: shortanesthesia onset time, no need for an anesthesiologist, can be used to all patients, even in those on anticoagulation treatments, intraoperative collaboration with the patient with assessment of his/her active movements, short hospital stay, and lastbut not least, the reduced costs of the surgical 
interventions. Due to its safety and simplicity and other many advantages, this technique has been used lately for a wide range of surgical interventions.

Muller Camillo Theoin PRS - global open report, in 2018 the first TM] arthroplasty using articular implants [23]. Also, the technique of local anesthesia with epinephrine is used in the surgical treatment of phalangeal and metacarpal fractures, hand flexor tendonrepair, tendon transfers in the upper limb, arthroscopy and open repair of the triangular fibrocartilage complex (TFCC), trapeziectomy for TMJ [23].

Gunasagaran et al. [25] in a study of 86 TF cases surgically treated using the WALANT technique reported no case of finger necrosis [24]. Liu B. reports a study in which WALANT technique was used to perform arthroscopies, demonstrating its advantage in visualizing both static and dynamic movements of the joint,the possible intraoperative collaboration with the patient and intraoperative observation of the functioning of various anatomical elements.

Tang J.B. et al. [26] report a study conducted in two major Chinese centers on an impressive group of 12,000 patients in which the technique of local anesthesia with epinephrine, WALANTwas used in hand traumas, softtissue tumor excision and flap transfers to the hand, once again demonstrating the efficacy and safety of WALANT technique, its cost-effectiveness, patient satisfaction, without an increase in infectionrate. Li Y.S. extends the area using local anesthesia for ankle fracture ORIF in a group of 13 patients, the used solution being 1\% lidocaine and 1:40,000 epinephrine. This study did not report any complications or need for supplementation with another form of anesthesia in none of the cases [27].

\section{Conclusions}

Local anesthesia technique using $1 \%$ lidocaine and 1 : 100,000 epinephrine solution can be used safely in hand and orthopedic surgery, providing the bloodless surgical field useful in these situations while avoiding the application of tourniquet and sedation without affecting the accuracy of surgery, good patient comfort and minimal use of material resources.

\footnotetext{
Abreviations

WALANT - wide awake local anesthesia no tourniqet

CTS - carpal tunnel syndrome

DD - dupuytren disease

TF - trigger finger

FPL - flexor pollicis longus

$M$ - male

$\mathrm{F}$ - female

TMJ - trapezo-metacarpian joint

ORIF - open reduction and internal fixation
}

\section{References}

1.NODWELL, T., LALONDE, D.H., Can. J. Plast. Surg., 11, no. 4, 2003, p. 187.

2.LALONDE, D.H., BELL, M., BENOIT, P., SPARKES, G., DENKLER, K., CHANG, P., J. Hand. Surg. Atll., 30, no. 5, 2005, p. 1061.

3.FITZCHARLES-BOWE, C., DENKLER, K.A., LALONDE, D.H., Hand., 2, no. 1, 2007, p. 5.

4. LI, Y.S., CHEN, C.Y., LIN, K.C., TARNG, Y.W., HSU, C.J., CHANG, W.N., Injury., 50, no. 4, 2019, p. 990.

5.LIU, B., NG, C.Y., ARSHAD, M.S., EDWARDS, D.S., HAYTON M.J ., Hand. Clin., 35, no. 1, 2019, p. 85.

6. XING, S.G., TANG, J.B., Hand. Clin., 35, no.1, 2019, p. 97.

7.HUANG, Y.C., CHEN, C.Y., LIN, K.C., YANG, S.W., TARNG, Y.W., CHANG, W.N., Orthopedics., 42, no. 1, 2019, p. e93.

8. AHMAD, A.A., YI, L.M., AHMAD, A.R., J. Hand. Surg. Am., 43, no. 11, 2018, p. 1045.el.

9. ORBACH, H., ROZEN, N., RUBIN, G., J. Int. Med. Res., 46, no. 10, 2018, p. 4269.

10.MULLER, C.T., CHRISTEN, T., HEIDEKRUGER, P.I., LAMOUILLE, J., RAFFOUL, W., MCKEE, D., LALONDE, D.H., DURAND, S., Plast. Reconstr. Surg. Glob. Open., 6, no. 4, 2018, p. el714.

11.LALONDE, D.H., J. Hand. Surg. Eur., 42, no. 9, 2017, p. 886.

12.WILHELMI, B.J., BLACKWELL, S.J ., MIKKER, J.H., MANCOLL, J.S., DARDANO, T., TRAN, A., PHILLIPS, L.G., Plast. Reconstr. Surg., 107, no. 2, 2001, p. 393.

13.CHOWDHRY, S., SEIDENSTRICKER, L., COONEY, D.S., HAZANI, R., WILHELMI, B.J ., Plast. Reconstr. Surg., 126, no. 6, 2010, p. 2031.

14.MANN, T., HAMMERT, W.C., J. Hand. Surg. Am., 37, no. 6, 2012, p. 1254.

15.LALONDE, D.H., MARTIN, A., J., Am. Acad. Orthop. Surg., 21, no. 8 , 2013, p. 443.

16.MCKEE, D.E., LALONDE, D.H., THOMA, A., GLENNIE, D.L., HAYWARD, J.E., Plast. Reconstr. Surg., 131, no.4, 2013, p. 811.

17. LALONDE, D., WONG, A., Plast. Reconstr. Surg., 134, no. 4, 2014, p. 9 S.

18.PIRES-NETO, P. ., MOREIRA, L.A., LAS-CASAS, P.P., Rev. Bras. Ortop., 52, no. 4, 2017, p. 383.

19.PERTEA, M., POROCH, V., GROSU, O.M., LUNCA, S., Rev. Chim. (Bucharest), 69, no. 1, 2018, p. 169.

20.ZHU, A.F., HOOD, B.R., MORRIS, M.S., OZER, K., J. Hand. Surg. Am., 42, no. 6, 2017, p. 479.e1.

21.HUTCHINSON, D.T., MCCLINTON, M.A., J. Hand. Surg. Am., 18, no. 2, 1993, p. 206.

22.MAURY, A., ROY, W., J. Hand. Surg. Br., 27, no. 4, 2002, p. 359.

23.MÜLLER, C.T., CHRISTEN, T., HEIDEKRUGER, P.I., LAMOUILLE, J., RAFFOUL, W., MCKEE, D., LALONDE, D.H., DURAND, S., Plast. Reconstr. Surg. Glob. Open., 6, no. 4, 2018, p. 1714.

24.GUNASAGARAN, J., SEAN, E.S., SHIVDAS, S., AMIR, S., AHMAD, T.S., J. Orthop. Surg., 25, no. 3, 2018, p. 1.

25.LIU, B., NG C.Y., ARSHAD, M.S., EDWARDS, D.S., HAYOTON, M.J., Hand. Clin., 35, no. 1, 2019, p. 85.

26.TANG, J.B., GONG, K.T., ZHU, L., PAN, Z.J ., XING, S.G., Hand. Clin., 33, no. 3, 2017, p. 415.

27.LI, Y.S., CHEN, C.Y., LIN, K.C., TARNG, Y.W., HSU, C.J., CHANG, W.N., Injury., 50, no. 4, 2019, p. 990.

Manuscript received: 26.09 .2019 